\title{
Epidemiology and clinical presentation of stroke in Upper Egypt (desert area)
}

\author{
This article was published in the following Dove Press journal: \\ Neuropsychiatric Disease and Treatment \\ 21 August 2015 \\ Number of times this article has been viewed
}

\author{
Hamdy N El Tallawy' \\ Wafaa M Farghaly' \\ Reda Badry' \\ Nermin A Hamdy ${ }^{2}$ \\ Ghaydaa A Shehata' \\ Tarek A Rageh' \\ Nabil A Metwally ${ }^{3}$ \\ Enas M Hassan ${ }^{2}$ \\ Sayed S Elsayed ${ }^{2}$ \\ Mohamed A Yehia ${ }^{2}$ \\ Wael T Soliman ${ }^{2}$ \\ 'Department of Neurology and \\ Psychiatry, Assiut University, Assiut, \\ ${ }^{2}$ Department of Neurology, El Minia \\ University, El-Minia City, ${ }^{3}$ Department \\ of Neurology, Al-Azhar University \\ (Assuit Branch), Assiut, Egypt
}

\begin{abstract}
Background: Stroke is a common cause of morbidity and mortality worldwide. Four out of five strokes occur in the low- and middle-income countries. This study aims to find lifetime prevalence of stroke in Upper Egypt and to identify clinical presentations and possible risk factors of stroke in this population.

Methods: This is a door-to-door (every door) study conducted on all inhabitants in Al Kharga district (representative of western desert) and Al Quseir city (representative of eastern desert). The study was conducted in two stages, and every stage consisted of three phases (screening, diagnostic, and investigatory).

Results: The total lifetime prevalence of stroke was $8.5 / 1,000$ in the population aged 20 years and more. It increased with advancing age and was higher among males than females among all age groups except in the childbearing period ( 20 years to $<40$ years of age). Lifetime prevalence of ischemic stroke $(7.2 / 1,000)$ was higher than hemorrhagic stroke $(1.1 / 1,000)$. Hemiparesis and hemiplegia were the commonest presentation of stroke. Headache, vomiting, and vertigo were found to be significantly more common accompaniments of hemorrhagic stroke. The most common risk factor was hypertension, followed by hyperlipidemia and diabetes mellitus.

Conclusion: The total lifetime prevalence of stroke in the population aged 20 years and more in Upper Egypt (desert area) lies within the range that is recorded in developing countries. Clinical presentation and risk factors are similar to those recorded from developing and developed countries.
\end{abstract}

Keywords: stroke, epidemiology, Upper Egypt, desert area

\section{Introduction}

According to the World Health Organization, around 15 million people, worldwide, suffer from stroke each year. Among these, five million die and another five million are permanently disabled. Four out of five strokes occur in the low- and middle-income countries who can least afford to manage the consequences of this disease. ${ }^{1}$

Stroke prevalence in the United Kingdom is $\sim 5 / 1,000$ population, ${ }^{2}$ while the range can be higher in developing countries $(5-10 / 1,000) .{ }^{3}$ Moreover, research has shown that the Middle East region faces a double burden of the disease due to decreasing rates of communicable diseases and the growing rates of noncommunicable diseases. ${ }^{4}$

Arterial hypertension, diabetes mellitus, cigarette smoking, hyperlipidemia, and advancing age have been identified as risk factors for stroke. ${ }^{5,6}$

The aim of this study was to find age-specific prevalence of stroke in Upper Egypt and to identify clinical presentations and risk factors of stroke in this population.

\section{Population and methods}

This door-to-door (every door) study was carried out on all inhabitants of Al Kharga district, New Valley ( $\mathrm{n}=62,583-13,915$ families; 78 families refused to participate) and Al Quseir city, Red Sea Governorate ( $n=33,285-7,590$ families of whom 93 families
Department of Neurology and Psychiatry, Assiut University, PO Box 71526,

Assiut, Egypt

Tel +20 2882369541

Email redaalbadry02@gmail.com 
refused to participate in this study) (total population: 95,868). The study was conducted on two stages. The first stage was conducted in Al Kharga district from January 1, 2006 to July 31,2008 , and the second stage was conducted in Al Quseir city from July 1, 2009 to January 31, 2012.

The study areas are representative of two desert areas of Upper Egypt, Western desert (Al Kharga district) and Eastern desert (Al Quseir city).

Western desert covers an area of $700,000 \mathrm{~km}^{2}$, thereby accounting for around two-thirds of Egypt's total land area. The government has considered the western desert a frontier region and has divided it into two governorates at approximately the 28 parallel; Matrouh to the north and New Valley to the south. Eastern desert is relatively mountainous. The desert environment extends all the way to the Red Sea coast (http:en.wikpedia.org/wiki/Geography-of-Egypt).

\section{Methods}

Each stage was conducted in three phases:

Phase 1: Screening phase: Screening of all inhabitants was performed by three neurologists, using a standardized Arabic screening questionnaire. ${ }^{7}$

Phase 2: Diagnostic phase: All patients had history suggestive of stroke or suspected through questionnaire were invited to attend general hospital of Al Kharga or Al Quseir, where clinical evaluation was done by another staff member in a special questionnaire prepared specially for this study.

Phase 3: Investigatory Phase: Stroke patients were invited to attend Assiut University Hospital for full clinical evaluation by staff members of neurology department and full investigations were done to verify clinical, etiological, and pathological diagnosis; brain computed tomography and/or magnetic resonance imaging, blood picture, prothrombin time and concentration, international neutralization rate, blood sugar curve, serum uric acid, lipogram, etc; electrocardiogram, echocardiography, and electroencephalogram when indicated. All study steps were approved by the Ethics Committee from the Faculty of Medicine, Assiut University.

\section{Statistical methods}

The data were coded and verified prior to data entry. The Statistical Package of SPSS version 16 for windows was used for data entry and analysis (SPSS Inc., Chicago, IL, USA). Descriptive statistics were calculated. For qualitative data, chi-square test was used, and for quantitative data, Student's $t$-test (for two groups) was used. $Z$-test was used to compare proportions and correlations. A significant $P$-value was considered when the $P$-value was less than 0.05 .

\section{Results}

In this study, 477 patients were detected with stroke (age

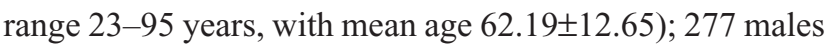
$(58.1 \%)$ with mean age $63.52 \pm 12.05$ and 200 females (41.9\%) with mean age $60.35 \pm 13.25(P=0.007)$.

Demographic data of the patients are shown in Table 1. Males exceeded females, married patients constituted around half the patients, and illiterate patients were more than educated patients.

Only one case was detected under the age of 20 years. The total age-specific prevalence of stroke among the population aged 20 years and more $(n=55,664)$ was $8.5 / 1,000$ population (Table 2). It increased with advancing age and was higher among males than females except among young adult group ( 20 years to $<40$ years).

Age-specific prevalence of ischemic stroke (7.2/1,000) was higher than hemorrhagic stroke $(1.1 / 1,000)$, and prevalence increased with age in both types. Males outnumbered females in all subtypes of stroke $(57.1 \%$ in transient ischemic attacks [TIAs], 57.4\% in ischemic, and $62.5 \%$ of hemorrhagic strokes). TIAs were underevaluated (Table 3 ).

Clinical presentation of stroke in patients according to the age groups is shown in Table 4, while those related to subtypes of stroke are shown in Table 5. The general manifestations of increased intracranial tension are higher among young adults ( 20 years to $<40$ years), while focal symptoms and signs are more common among older age

Table I Demographic data of stroke patients in Upper Egypt (desert area)

\begin{tabular}{|c|c|c|c|c|}
\hline & $\begin{array}{l}\text { Age } 20 \text { to } \\
<40 \text { (years) }\end{array}$ & $\begin{array}{l}\text { Age } 40 \text { to } \\
<60 \text { (years) }\end{array}$ & $\begin{array}{l}\text { Age 60+ } \\
\text { (years) }\end{array}$ & Total \\
\hline Number & $21(4.4 \%)$ & 167 (35\%) & 289 (60.6\%) & 477 \\
\hline \multicolumn{5}{|l|}{ Sex } \\
\hline Males & $8(38.1 \%)$ & 97 (58.1\%) & I 72 (59.5\%) & 277 (58.1\%) \\
\hline Females & $13(61.9 \%)$ & 70 (4I.9\%) & 117 (40.5\%) & 200 (41.9\%) \\
\hline \multicolumn{5}{|l|}{ Marital status } \\
\hline Single & 6 (28.6\%) & 43 (25.7\%) & 59 (20.4\%) & 108 (22.6\%) \\
\hline Married & 15 (7I.4\%) & 105 (62.9\%) & 145 (50.2\%) & 265 (55.6\%) \\
\hline Divorced & 0 & $6(3.6 \%)$ & $3(1.0 \%)$ & $9(1.9 \%)$ \\
\hline Widow & 0 & $13(7.8 \%)$ & $82(28.4 \%)$ & 95 (19.9\%) \\
\hline \multicolumn{5}{|l|}{ Education } \\
\hline Illiterate & $2(9.5 \%)$ & 55 (32.9\%) & 190 (65.7\%) & 247 (5I.8\%) \\
\hline Educated & 19 (90.5\%) & $112(67.1 \%)$ & 99 (34.3\%) & 230 (48.2\%) \\
\hline \multicolumn{5}{|l|}{ Occupation } \\
\hline Unemployed & I (4.8\%) & 0 & $2(0.7 \%)$ & $3(0.6 \%)$ \\
\hline Employee & $10(47.6 \%)$ & 86 (5I.5\%) & $26(9.0 \%)$ & $122(25.6 \%)$ \\
\hline Professor & 0 & $2(1.2 \%)$ & 0 & $2(0.4 \%)$ \\
\hline Housewife & 5 (23.8\%) & 35 (21.0\%) & 94 (32.5\%) & 134 (28.1\%) \\
\hline Farmer & $2(9.6 \%)$ & $16(9.6 \%)$ & 25 (8.6\%) & $43(9.0 \%)$ \\
\hline On pension & 0 & $9(5.4 \%)$ & $109(37.7 \%)$ & II 8 (24.7\%) \\
\hline Others & $3(14.3 \%)$ & 19 (11.4\%) & 33 (II.4\%) & 55 (II.5\%) \\
\hline
\end{tabular}

Note: Data are presented as $\mathrm{n}(\%)$. 
Table 2 Age- and sex-specific prevalence of stroke/I,000 population in Upper Egypt (desert area)

\begin{tabular}{|c|c|c|c|c|c|c|}
\hline \multirow[t]{2}{*}{ Age group } & \multicolumn{2}{|c|}{ Total population, $N=55,664$} & \multicolumn{2}{|c|}{ Males, $\mathbf{N}=\mathbf{2 8 , 3 6 5}$} & \multicolumn{2}{|c|}{ Females, $\mathbf{N}=27,299$} \\
\hline & $\mathbf{N}$ & Prev/I,000 & $\mathbf{N}$ & Prev/I,000 & $\mathbf{N}$ & Prev/I,000 \\
\hline 20 to $<40$ years & $21 / 31,998$ & 0.65 & $8 / 15,760$ & 0.5 & $13 / 16,238$ & 0.8 \\
\hline 40 to $<60$ years & $167 / 17,622$ & 9.4 & $97 / 9,127$ & 10.6 & $70 / 8,495$ & 8.2 \\
\hline$\geq 60$ years & $289 / 6,044$ & 47.8 & $172 / 3,478$ & 49.4 & $117 / 2,566$ & 45.5 \\
\hline Total & $477 / 55,664$ & 8.5 & $277 / 28,365$ & 9.7 & $200 / 27,299$ & 7.3 \\
\hline
\end{tabular}

Note: Only one case was detected below the age of 20 years.

Abbreviation: Prev, prevalence.

Table 3 Age-specific prevalence of different subtypes of stroke/I,000 population in Upper Egypt (desert area)

\begin{tabular}{|c|c|c|c|c|c|c|}
\hline \multirow[t]{2}{*}{ Age group } & \multicolumn{2}{|c|}{ TIA } & \multicolumn{2}{|c|}{ Ischemic stroke } & \multicolumn{2}{|c|}{ Hemorrhagic stroke } \\
\hline & $\mathbf{N}$ & Prev/I,000 & $\mathbf{N}$ & Prev/I,000 & $\mathbf{N}$ & Prev/I,000 \\
\hline 20 to $<40$ years & 0 & 0 & 17 & 0.53 & 4 & 0.12 \\
\hline 40 to $<60$ years & 5 & 0.28 & 136 & 7.7 & 26 & 1.4 \\
\hline$\geq 60$ years & 2 & 0.33 & 253 & 41.8 & 34 & 5.6 \\
\hline Total & 7 & 0.12 & 406 & 7.2 & 64 & I.I \\
\hline
\end{tabular}

Abbreviations: TIA, transient ischemic attack; Prev, prevalence.

Table 4 Clinical presentation of stroke patients in Upper Egypt (desert area)

\begin{tabular}{|c|c|c|c|c|}
\hline \multirow[t]{2}{*}{ Clinical presentation } & \multirow{2}{*}{$\begin{array}{l}\text { Age } 20 \text { to }<40 \text { (years) } \\
\mathrm{n}=\mathbf{2 1}\end{array}$} & \multirow{2}{*}{$\begin{array}{l}\text { Age } 40 \text { to }<60 \text { (years) } \\
n=167\end{array}$} & \multirow{2}{*}{$\begin{array}{l}\text { Age } 60+\text { (years) } \\
\mathrm{n}=\mathbf{2 8 9}\end{array}$} & \multirow{2}{*}{$\begin{array}{l}\text { Total } \\
\mathrm{n}=477\end{array}$} \\
\hline & & & & \\
\hline \multicolumn{5}{|l|}{ Side of the body } \\
\hline Right & $12(57.1 \%)$ & $100(59.9 \%)$ & I 34 (46.4\%) & $246(51.6 \%)$ \\
\hline Left & $8(38.1 \%)$ & $62(37.1 \%)$ & $136(47.1 \%)$ & 206 (43.2\%) \\
\hline Bilateral & I (4.8\%) & $5(3.0 \%)$ & $19(6.6 \%)$ & $25(5.2 \%)$ \\
\hline Impaired conscious & II (52.4\%) & $43(25.7 \%)$ & $8 \mathrm{I}(28.0 \%)$ & I 35 (28.3\%) \\
\hline Seizure & $5(23.8 \%)$ & $22(13.2 \%)$ & $24(8.3 \%)$ & $51(10.7 \%)$ \\
\hline Vomiting & $5(23.8 \%)$ & $20(12.0 \%)$ & $42(14.5 \%)$ & 67 (14.0\%) \\
\hline Vertigo & $5(23.8 \%)$ & $26(15.6 \%)$ & 61 (21.1\%) & $92(19.3 \%)$ \\
\hline Headache & $12(57.1 \%)$ & 68 (40.7\%) & $108(37.4 \%)$ & 188 (39.4\%) \\
\hline Mental depression & $2(9.5 \%)$ & 33 (19.8\%) & $55(19.0 \%)$ & 90 (18.9\%) \\
\hline Psychotic & I (4.8\%) & $5(3 \%)$ & $21(7.3 \%)$ & $27(5.7 \%)$ \\
\hline CrN-UMN & $10(47.6 \%)$ & II (70.7\%) & $204(70.6 \%)$ & $332(69.6 \%)$ \\
\hline LMN & 0 & $7(4.2 \%)$ & $3(1.0 \%)$ & $10(2.1 \%)$ \\
\hline \multicolumn{5}{|l|}{ Speech } \\
\hline Dysarthria/anarthria & $4(19.1 \%)$ & $6 \mathrm{I}(36.5 \%)$ & $112(38.1 \%)$ & 177 (37.1\%) \\
\hline Dysphasia/aphasia & 0 & 14 (8.4\%) & $18(6.2 \%)$ & $32(6.7 \%)$ \\
\hline \multicolumn{5}{|l|}{ Motor } \\
\hline Hemiparesis & $12(57.1 \%)$ & I 33 (79.6\%) & $220(76.1 \%)$ & 365 (76.5\%) \\
\hline Quadriparesis & $2(9.5 \%)$ & $17(10.2 \%)$ & $48(16.6 \%)$ & $67(14.0 \%)$ \\
\hline Ataxia & I (4.8\%) & $3(1.8 \%)$ & II (3.8\%) & $15(3.1 \%)$ \\
\hline \multicolumn{5}{|l|}{ Sphincter } \\
\hline Precipitancy or incontinence & $6(28.5 \%)$ & $28(16.8 \%)$ & $93(32.1 \%)$ & $127(26.6 \%)$ \\
\hline Hemihypesthesia & $5(23.8 \%)$ & 57 (34.1\%) & $68(23.5 \%)$ & I $30(27.3 \%)$ \\
\hline \multicolumn{5}{|l|}{ Gait } \\
\hline Circumduction & $6(28.6 \%)$ & 68 (40.7\%) & $92(31.8 \%)$ & $166(34.8 \%)$ \\
\hline Walk aided & 0 & $16(9.6 \%)$ & $66(22.8 \%)$ & $82(17.2 \%)$ \\
\hline Bed bound & I (4.8\%) & $18(10.8 \%)$ & $56(19.4 \%)$ & 75 (I5.7\%) \\
\hline Shuffling & 0 & 0 & I3 (4.5\%) & $13(2.7 \%)$ \\
\hline Wide base & 0 & I (6.0\%) & 7 (2.4\%) & $8(1.7 \%)$ \\
\hline
\end{tabular}

Note: Data are presented as $\mathrm{n}(\%)$.

Abbreviations: UMN, upper motor neuron; LMN, lower motor neuron; $\mathrm{CrN}$, cranial nerves. 
Table 5 Clinical presentation in different types of stroke in Upper Egypt (desert area)

\begin{tabular}{|c|c|c|c|c|}
\hline Clinical presentation & $\begin{array}{l}\text { TIA } \\
n=7\end{array}$ & $\begin{array}{l}\text { Infarction } \\
\mathrm{n}=406\end{array}$ & $\begin{array}{l}\text { Hemorrhage } \\
n=64\end{array}$ & $P$-value \\
\hline Side & & & & 0.63 \\
\hline Right & $4(57.1 \%)$ & $214(52.7 \%)$ & $28(43.8 \%)$ & \\
\hline Left & $3(42.9 \%)$ & 170 (4I.9\%) & $33(51.6 \%)$ & \\
\hline Bilateral & 0 & $22(5.4 \%)$ & $3(4.7 \%)$ & \\
\hline Impaired consciousness & I (I4.3\%) & 97 (23.9\%) & $36(56.2 \%)$ & 0.000 \\
\hline Seizures & I (14.3\%) & $41(10.1 \%)$ & $9(14.1 \%)$ & 0.60 \\
\hline Vomiting & 0 & $34(8.4 \%)$ & $33(51.6 \%)$ & 0.000 \\
\hline Vertigo & 0 & $70(17.2 \%)$ & $22(34.4 \%)$ & 0.002 \\
\hline Headache & $2(28.6 \%)$ & $133(32.8 \%)$ & 53 (82.8\%) & 0.000 \\
\hline Mental depression & $2(28.6 \%)$ & 78 (19.2\%) & $10(15.6 \%)$ & 0.63 \\
\hline Psychosis & I (I4.3\%) & $26(6.4 \%)$ & 0 & 0.07 \\
\hline CrN-UMN & I (I4.3\%) & $277(68.2 \%)$ & 54 (84.4\%) & 0.000 \\
\hline LMN & 0 & $10(2.5 \%)$ & 0 & \\
\hline \multicolumn{5}{|l|}{ Speech } \\
\hline Dysarthria/anarthria & I (I4.3\%) & 154 (37.9\%) & $22(34.3 \%)$ & 0.16 \\
\hline Dysphasia/aphasia & 0 & $24(5.9 \%)$ & $8(12.4 \%)$ & \\
\hline \multicolumn{5}{|l|}{ Motor deficit } \\
\hline Hemiparesis & $4(57.2 \%)$ & $314(77.3 \%)$ & 47 (73.4\%) & 0.005 \\
\hline Quadriparesis & 0 & $54(13.3 \%)$ & $13(20.3 \%)$ & \\
\hline Ataxia & I (I4.3\%) & $13(3.2 \%)$ & I (I.6\%) & \\
\hline
\end{tabular}

Note: Data are presented as $\mathrm{n}(\%)$.

Abbreviations: TIA, transient ischemic attack; $\mathrm{CrN}$, cranial nerves; UMN, upper motor neuron; LMN, lower motor neuron.

groups. Also, manifestations of increased intracranial tension are significantly higher among hemorrhagic stroke than the other subtypes.

Table 6 shows the frequency of risk factors among stroke patients. The most common risk factor for stroke was hypertension, which was observed among $64 \%$ of all stroke cases, followed by hyperlipidemia and diabetes mellitus (DM). Risk factors for each subtype of stroke are shown in Table 7. Hypertension was more prevalent among patients with hemorrhagic strokes, while diabetes and hyperlipidemia were more among ischemic stroke patients. Number of risk factors was significantly correlated with age $(P<0.000)$.

Of all stroke cases, $12.9 \%$ of patients had recurrent stroke. Recurrence was not correlated to age, sex, or risk factors except for diabetes $(P=0.02)$ and was significantly more among patients with ischemic stroke.

\section{Discussion}

The lifetime prevalence of stroke, among population aged 20 years and more, was 8.5/1,000 population, which

Table 6 Frequency of risk factors among stroke patients in Upper Egypt (desert area)

\begin{tabular}{|c|c|c|c|c|c|}
\hline & $\begin{array}{l}\text { Age } 20 \text { to }<40 \text { (years), } \\
n=21\end{array}$ & $\begin{array}{l}\text { Age } 40 \text { to }<60 \text { (years), } \\
n=167\end{array}$ & $\begin{array}{l}\text { Age } 60+\text { (years), } \\
n=289\end{array}$ & $\begin{array}{l}\text { Total, } \\
n=477\end{array}$ & $P$-value \\
\hline HTN & 4 (I9.0\%) & 109 (65.3\%) & 195 (67.5\%) & $308(64.6 \%)$ & 0.000 \\
\hline Hyperlipidemia & $8(38.1 \%)$ & $89(53.3 \%)$ & 157 (54.3\%) & $254(53.2 \%)$ & 0.11 \\
\hline DM & I (4.7\%) & 54 (32.3\%) & $109(37.7 \%)$ & 164 (34.4\%) & 0.007 \\
\hline \multicolumn{6}{|l|}{ Smoking } \\
\hline Ex-smoker & I (4.7\%) & 26 (15.5\%) & 54 (I8.6\%) & 81 (16.9\%) & 0.26 \\
\hline Smoker & $5(23.8 \%)$ & $38(22.7 \%)$ & 52 (I7.9\%) & 95 (19.9\%) & \\
\hline Previous stroke & I (4.7\%) & 19 (11.4\%) & 42 (I4.5\%) & 62 (12.9\%) & 0.32 \\
\hline Cardiac & $2(9.5 \%)$ & 17 (10.2\%) & $22(7.6 \%)$ & $4 \mathrm{l}(8.6 \%)$ & 0.53 \\
\hline Positive FH & $2(9.5 \%)$ & $11(6.6 \%)$ & II (3.8\%) & 24 (5.0\%) & 0.26 \\
\hline \multicolumn{6}{|l|}{ No of risk factors } \\
\hline Not recorded & $4(19.0 \%)$ & 7 (4.2\%) & I (0.3\%) & 12 (2.5\%) & 0.001 \\
\hline One factor & $10(47.6 \%)$ & $35(21.0 \%)$ & $20(6.9 \%)$ & 65 (13.6\%) & \\
\hline Two factors & $4(19.0 \%)$ & $50(29.9 \%)$ & 47 (16.3\%) & $101(21.2 \%)$ & \\
\hline Three factors & 3 (14.4\%) & 4I (24.6\%) & 85 (29.4\%) & $129(27.0 \%)$ & \\
\hline Four or more & 0 & $34(20.3 \%)$ & $136(47.1 \%)$ & $170(35.7 \%)$ & \\
\hline
\end{tabular}

Note: Ratio of smokers was related to males only as there were no recorded female smokers or ex-smokers. Data are presented as $\mathrm{n}(\%)$. Abbreviations: HTN, hypertension; DM, diabetes mellitus; FH, family history of stroke. 
Table 7 Frequency of risk factors among different subtypes of patients in Upper Egypt (desert area)

\begin{tabular}{|c|c|c|c|c|}
\hline & $\begin{array}{l}\text { TIA } \\
n=7\end{array}$ & $\begin{array}{l}\text { Infarction } \\
n=406\end{array}$ & $\begin{array}{l}\text { Hemorrhage } \\
\mathrm{n}=64\end{array}$ & $P$-value \\
\hline HTN & 4 (57.1\%) & 252 (62.6\%) & 52 (81.2\%) & 0.01 \\
\hline DM & I (I4.2\%) & 148 (36.5\%) & 15 (23.4\%) & 0.06 \\
\hline \multicolumn{5}{|l|}{ Smoking } \\
\hline Ex-smoker & 0 & 70 (I7.2\%) & II (I7.1\%) & 0.12 \\
\hline Smoker & $4(57.1 \%)$ & 81 (19.9\%) & $10(15.6 \%)$ & \\
\hline Cardiac & 0 & 37 (9.1\%) & $4(6.2 \%)$ & 0.48 \\
\hline Hyperlipidemia & $2(28.6 \%)$ & 220 (54.2\%) & $32(50.0 \%)$ & 0.43 \\
\hline Positive FH & 0 & $22(5.4 \%)$ & $2(3.1 \%)$ & 0.61 \\
\hline Previous stroke & 0 & 57 (14\%) & $3(4.7 \%)$ & 0.05 \\
\hline \multicolumn{5}{|l|}{ No of risk factors } \\
\hline Not recorded & 0 & II (2.7\%) & I (I.6\%) & 0.27 \\
\hline One factor & I (I4.3\%) & $53(13.1 \%)$ & II (I7.I\%) & \\
\hline Two factors & $3(42.8 \%)$ & 80 (19.7\%) & 18 (28.1\%) & \\
\hline Three factors & $2(28.6 \%)$ & $110(27.1 \%)$ & $17(26.6 \%)$ & \\
\hline Four or more & I (14.3\%) & 152 (37.4\%) & $17(26.6 \%)$ & \\
\hline
\end{tabular}

Note: Data are presented as $\mathrm{n}(\%)$.

Abbreviations: TIA, transient ischemic attack; HTN, hypertension; DM, diabetes mellitus; FH, family history of stroke.

lies within the range $(5-10 / 1,000)$ that was recorded in developing countries. ${ }^{3}$ Prevalence showed a steady increase with advancing age. This is in agreement with most studies of stroke, which concluded that age has been identified as a marker of risk for stroke. ${ }^{8,9}$

Prevalence was higher among males than females except for the young adult group ( 20 to $<40$ years), where stroke prevalence was higher among females than males. Males also outnumbered females in all subtypes of stroke, and this is in agreement with previous epidemiological studies, which have reported that compared with women, stroke strikes men more often. ${ }^{10,11}$ The hormonal constitutional factors plus the higher rate of smoking and higher rate of stressful situations among males than females (most females are housewives) may explain this higher prevalence of stroke among males. On the other hand, the significant predominance of stroke among young adult females ( 20 to $<40$ years of age) can be attributed to complications of pregnancy and labor during this childbearing period. Moreover, this could be related to the higher frequencies of migraine and/or oral contraceptive use among females during this age group. ${ }^{12}$

Ischemic stroke was the predominant subtype in this study $(85.1 \%)$, which is in agreement with most stroke studies. El Sayed et $a l^{13}$ stated that the most frequent stroke subtype in Saudi Arabia was ischemic infarcts (79\%), followed by intracerebral hemorrhage (18.8\%) and sun arachnoid hemorrhage (2.2\%). Studies from India confirmed that the incidence of ischemic stroke was higher when compared with the other types. ${ }^{14}$

TIAs had a prevalence of $0.12 / 1,000$, which might be underestimated compared to a total population prevalence of
22/1,000, in population-based studies in the United States. ${ }^{15}$ This underestimation of TIA in the current study could be due to lack of health insurance system in the studied areas with subsequent delay in health-seeking advice for these spontaneously resolved symptoms.

Hemiparesis and hemiplegia were the commonest presentation of stroke $(76.5 \%)$, which is in agreement with Siddique et $\mathrm{a}^{16}$ and Omkar Prasad et al. ${ }^{17}$ Omkar Prasad et a ${ }^{17}$ found that the commonest clinical feature at presentation of stroke in India was hemiplegia ( $80 \%$ ), followed by dysarthria $(60 \%)$ and aphasia (59\%). In the current study, patients had less speech defects (37.1\% for dysarthria and $6.7 \%$ for aphasia). This difference could be attributed to the type of the study - whether a prospective or retrospective study like the present one.

Regarding the side of the lesion, $51.6 \%$ had right-sided lesions, in disagreement with other studies, which found that left hemisphere brain infarction was more common than right hemisphere lesion. ${ }^{16,17}$

Headache was recorded in $39 \%$ of patients in this study, which is lower than that in the study by Siddique et a ${ }^{16}$ who reported headache among $60 \%$ and vomiting among $75 \%$ of patients. Headache, vomiting, and vertigo were found to be significantly more common accompaniments of hemorrhagic stroke than other types of stroke, which is in agreement with Siddique et al. ${ }^{16}$

Impaired consciousness was reported in a higher rate (56.2\%) of patients with hemorrhagic stroke than ischemic strokes $(23.9 \%)$, which is in agreement with previous study. ${ }^{16}$ This high rate of impaired consciousness among hemorrhagic stroke patients could be attributed to the significantly higher concomitant rate of increased intracranial tension among 
patients with hemorrhagic stroke than ischemic stroke (82.8\% versus $32.8 \%$ for headache and $51.6 \%$ versus $8.4 \%$ for vomiting).

In a large epidemiological project, cerebrovascular diseases represented the most commonly identified etiology among patients with symptomatic epilepsy. ${ }^{18}$ Early poststroke seizures (within 15 days of stroke) are thought to result from cellular biochemical dysfunction, leading to electrically irritable tissues, while late-onset seizures are thought to be caused by gliosis and the development of a meningo-cerebral cicatrix. ${ }^{19}$ In the current study, poststroke seizures were recorded in $10.7 \%$ of patients, a ratio which was higher among patients with hemorrhagic stroke (14.1\%) than ischemic stroke (10.1\%), and is in close proximity to the rate observed in the prospective multicenter report $(8.6 \%)$ from the "Seizure After Stroke Study Group". ${ }^{20}$

The most common risk factors for stroke in this study were hypertension (64\%), followed by hyperlipidemia $(53.2 \%)$ and DM (34.4\%), which is in agreement with previous studies that found hypertension to be the commonest risk factor for stroke. Similarly, Alrajeh et $\mathrm{al}^{4}$ reported that the significant risk factors for stroke among Saudi population are hypertension followed by diabetes mellitus, heart disease, and smoking. It has been estimated that hypertension causes $54 \%$ of stroke in low-income and middle-income countries, followed by hypercholesterolemia (15\%) and tobacco smoking (12\%). ${ }^{22}$ More recent studies again found elevated blood pressure is by far the most important risk factor for stroke..$^{23,24}$

The mechanism by which hypertension alters cerebrovascular autoregulation is not completely understood, but likely to include a combination of effects on myogenic tone and on the changes on the mechanical characteristics of cerebral blood vessels induced by remodeling and stiffening. These changes in autoregulation are particularly damaging to the periventricular white matter, which is located at the boundary between different arterial territories and as such is most susceptible to hypoperfusion. ${ }^{25}$

Hypertension was significantly more encountered among hemorrhagic stroke $(81.2 \%)$ than ischemic stroke patients $(62.6 \%)$, which is in agreement with the study by Siddique et $\mathrm{al}^{16}$ who reported hypertension in $80 \%$ of patients with hemorrhagic stroke and $56.2 \%$ in ischemic stroke.

Smoking, diabetes, and hyperlipidemia were recorded in higher rates among ischemic strokes, and this is similar to results from a previous study done by Shinton and Beevers, ${ }^{25}$ who found that smoking was associated with $50 \%$ of hemorrhagic and $55 \%$ of ischemic stroke cases. He also found that cigarette smokers have an overall 51\% increased risk of having a stroke. Patients with diabetes are two to three times more likely to have ischemic stroke when compared with nondiabetic individuals. ${ }^{27,28}$ Diabetes mellitus was associated with $26.25 \%$ of ischemic stroke. ${ }^{16}$

The association between cholesterol and stroke is complicated because their relationship varies based upon the type of stroke and the type of cholesterol involved. People in the highest tertile of non-high-density lipoprotein to high-density lipoprotein ratio would have an increased risk of ischemic stroke compared to those in the lowest tertile. ${ }^{29}$

Heart diseases are considered a risk factor for stroke. People with atrial fibrillation are approximately five times more likely to have stroke compared to those who do not have the disease. People with coronary heart disease or chronic heart failure are approximately two to four times as likely to have stroke. ${ }^{30}$ In this study, heart diseases were recorded in $8.6 \%$ of stroke patients.

The cumulative risk of stroke recurrence within 5 years after a first episode ranges between $15 \%$ and $40 \%$. The most relevant predictors of stroke recurrence identified in epidemiological trials include advancing age, hypertension, atrial fibrillation, diabetes mellitus, hyperlipidemia, and previous TIA. ${ }^{31}$ In this study, previous stroke was reported in $12.9 \%$ of patients and was not correlated to age, sex, or risk factors except for diabetes $(P<0.5)$. Moreover, stroke recurrence was significantly more among patients with ischemic stroke.

Robert and Zamzami ${ }^{31}$ found positive family history of stroke in $14 \%$ of stroke patients in Saudi Arabia. In the current study, a lower rate (5\%) was recorded, which can be attributed to lower level of consanguinity among Egyptians compared to Saudi Arabian population.

Number of risk factors was significantly correlated with increasing age. While $20.3 \%$ of patients in the age group 40 years to $<60$ years had one risk factor, $47.1 \%$ of patients aged $60+$ had four and more risk factors for stroke.

\section{Conclusion}

The total lifetime prevalence of stroke in population aged 20 years and more in Upper Egypt (desert area) was $8.5 / 1,000$. It lies within the range that is recorded in developing countries. Prevalence showed a steady increase with advancing age and was higher among males. Ischemic stroke was the predominant subtype. Headache, vomiting, vertigo, and disturbed level of consciousness were found to be significantly more common accompaniments of hemorrhagic stroke. The most common risk factors for stroke 
were hypertension, followed by hyperlipidemia and diabetes mellitus. Clinical presentation and risk factors are similar to those recorded from developing and developed countries.

Limitations of this study were unavailability of neuroimaging techniques (computed tomography or magnetic resonance imaging) or most of the laboratory tools being available either in Al Kharga or in Al Quseir city. Also, transportation of patients to Assiut city (220 km from Al Kharga and $470 \mathrm{~km}$ far away from Al Quseir city) was difficult.

\section{Disclosure}

The authors report no conflicts of interest in this work.

\section{References}

1. Lopez AD, Mathers CD, Ezzati M, Jamison DT, Murray CJ. Global and regional burden of disease and risk factors, 2001: systematic analysis of population health data. Lancet. 2006;367(9524):1747-1757.

2. Poungvarin N. Stroke in the developing world. Lancet. 1998;352(suppl 3): SIII19-SIII22.

3. Akala FA, El-Saharty S. Public-health challenges in the Middle East and North Africa. Lancet. 2006;367(9515):961-964.

4. Al-Rajeh SM, Larbi EB, al-Freihi H, Ahmed K, Muhana F, Bademosi O. A clinical study of stroke. East Afr Med J. 1989;66(3):183-191.

5. Jowi JO, Mativo PM. Pathological sub-types, risk factors and outcome of stroke at the Nairobi Hospital, Kenya. East Afr Med J. 2008; 85(12):572-581.

6. Benamer HT, Grosset D. Stroke in Arab countries: a systematic literature review. J Neurol Sci. 2009;284(1-2):18-23.

7. El Tallawy HN, Farghaly WM, Rageh TA, et al. Epidemiology of major neurological disorders project in Al Kharga district, New Valley, Egypt. Neuroepidemiology. 2010;35(4):291-297.

8. Al-Rajeh S, Larbi EB, Bademosi O, Awada A, Yousef A, al-Freihi H. Stroke register: experience from the eastern province of Saudi Arabia. Cerebrovasc Dis. 1998;8(2):86-89.

9. Orzuza G, Zurru MC. Epidemiological aspects of stroke in very old patients. Cardiovasc Hematol Disord Drug Targets. 2011;11(1):2-5.

10. Appelros P, Stegmayr B, Terent A. Sex differences in stroke epidemiology: a systematic review. Stroke. 2009;40(4):1082-1090.

11. Maeda K, Toyoda K, Minematsu K, Kobayashi S. Effects of sex difference on clinical features of acute ischemic stroke in Japan. J Stroke Cerebrovasc Dis. 2013;22:1070-1075.

12. Rasura M, Spalloni A, Ferrari M, et al. A case series of young stroke in Rome. Eur J Neurol. 2006;13:146-152.

13. El Sayed MM, Adeuja AO, El-Nahrawy E, Olaish MA. Characteristics of stroke in Hofuf, Saudi Arabia. Ann Saudi Med. 1999;19(1):27-31.
14. Sridharan SE, Unnikrishnan JP, Sukumaran S, et al. Incidence, types, risk factors, and outcome of stroke in a developing country: the Trivandrum stroke registry. Stroke. 2009;40:1212-1218.

15. Easton JD, Saver JL, Albers GW, et al. Definition and evaluation of transient ischemic attack: a scientific statement for healthcare professionals from the American heart association/American stroke association stroke council; council on cardiovascular radiology and intervention; council on cardiovascular nursing; and the interdisciplinary council on peripheral vascular disease. Stroke. 2009;40:2276-2293.

16. Siddique A, Nur Z, Mahbub S, Alam B, Miah T. Clinical presentation and epidemiology of stroke: a study of 100 cases. J Med. 2009;10: 86-89.

17. Omkar Prasad B, Susmita C, Ksh Gomti D. Clinico-epidemiological study of acute ischemic stroke in a tertiary hospital of northeastern state of India. Int J Biomed Adv Res. 2013;4:9.

18. Hauser WA, Annegers JF, Kurland LT. Incidence of epilepsy and unprovoked seizures in Rochester, Minnesota; 1935-1984. Epilepsia. 1993; 34:453-468.

19. Camilo O, Goldstein L. Seizures and epilepsy after ischemic stroke. Stroke. 2004;35:1769-1775.

20. Bladin C, Alexandrov A, Bellavance A, et al. Seizures after stroke: a prospective multicenter study. Arch Neurol. 2000;57:1617-1622.

21. Strong K, Mathers C, Bonita R. Preventing stroke: saving lives around the world. Lancet Neurol. 2007;6:182-187.

22. Lee M, Saver J, Chang B. Presence of baseline prehypertension and risk of incident stroke: a meta-analysis. Neurology. 2011;77:1330-1337.

23. Chalachew Misganaw A, Sofia Kebede B. Assessment of stroke patients: occurrence of unusually high number of haemorrhagic stroke cases in Tikur Anbessa Specialized Hospital, Addis Ababa, Ethiopia. Clin Med Res. 2013;2:94-100.

24. Faraco G, Iadecola C. Hypertension: a harbinger of stroke and dementia. Hypertension. 2013;62:810-817.

25. Shinton R, Beevers G. Meta-analysis of relation between cigarette smoking and stroke. BMJ. 1989;298:789-794.

26. Banerjee C, Moon YP, Paik MC. Duration of diabetes and risk of ischaemic stroke: the Northern Manhattan study. Stroke. 2012;34: 1212-1217.

27. Zhang Z, Yan J, Shi H. Hyperglycemia as a risk factor of ischemic stroke. J Drug Metab Toxicol. 2013;4:4.

28. O'Donnell MJ, Xavier D, Liu L. Risk factors for ischaemic and intracerebral haemorrhagic stroke in 22 countries (the INTERSTROKE study): a case-control study. Lancet. 2010;376:112-123.

29. Haeusler KG, Laufs U, Endres M. Chronic heart failure and ischemic stroke. Stroke. 2011;42:2977-2982.

30. Cámara AG, Arche JF, Vivas PF, et al. Recurrence after a first-ever ischemic stroke development of a clinical prediction rule. Res Neurol. 2013;2013:264063.

31. Robert A, Zamzami M. Stroke in Saudi Arabia: a review of the recent literature. Pan Afr Med J. 2014;17:14.
Neuropsychiatric Disease and Treatment

\section{Publish your work in this journal}

Neuropsychiatric Disease and Treatment is an international, peerreviewed journal of clinical therapeutics and pharmacology focusing on concise rapid reporting of clinical or pre-clinical studies on a range of neuropsychiatric and neurological disorders. This journal is indexed on PubMed Central, the 'PsycINFO' database and CAS,

\section{Dovepress}

and is the official journal of The International Neuropsychiatric Association (INA). The manuscript management system is completely online and includes a very quick and fair peer-review system, which is all easy to use. Visit http://www.dovepress.com/testimonials.php to read real quotes from published authors. 